\title{
Clot Detection
}

National Cancer Institute

\section{Source}

National Cancer Institute. Clot Detection. NCI Thesaurus. Code C111095.

Any of several methods used to detect the presence of or quantify the formation of a thrombus in a specimen. 